\title{
Corrigendum: Staphylococcus aureus Bacteriophage Suppresses LPS-Induced Inflammation in MAC-T Bovine Mammary Epithelial Cells
}

\author{
Lili Zhang, Xiang Hou, Lichang Sun, Tao He, Ruicheng Wei, Maoda Pang and Ran Wang* \\ Key Laboratory of Food Quality and Safety of Jiangsu Province-State Key Laboratory Breeding Base, Institute of Food Safety \\ and Nutrition, Jiangsu Academy of Agricultural Sciences, Nanjing, China
}

Keywords: Staphylococcus aureus, bacteriophage, inflammation, LPS, NF-кB, MAC-T cells

\section{A Corrigendum on}

Staphylococcus aureus Bacteriophage Suppresses LPS-Induced Inflammation in MAC-T Bovine Mammary Epithelial Cells

by Zhang, L., Hou, X., Sun, L., He, T., Wei, R., Pang, M., et al. (2018). Front. Microbiol. 9:1614. doi: $10.3389 /$ fmicb.2018.01614

In the original article, there was an error. We stated in the article that Previous studies reported that bacteriophages could activate NF- $\mathrm{B}$ signaling and enhance immune effects in vitro (Gorski et al., 2006). In fact, the authors of the aforementioned article reported the exact opposite; that is, they reported a phage-mediated down-regulation of NF- $\kappa \mathrm{B}$ activation.

A correction has been made to Discussion, Paragraph 3:

Previous studies reported that bacteriophages can diminish cellular infiltration of allogeneic skin allograft in mice, extend its survival and inhibit human $\mathrm{T}$ cell activation in vitro. Furthermore,

Edited by:

Pilar García,

Consejo Superior de Investigaciones Cientificas (CSIC), Spain

Reviewed by:

Andrzej Gorski,

Ludwik Hirszfeld Institute of Immunology and Experimental Therapy (PAN), Poland

*Correspondence:

Ran Wang

Wangran2001@126.com

Specialty section:

This article was submitted to

Antimicrobials, Resistance and

Chemotherapy,

a section of the journal

Frontiers in Microbiology

Received: 02 August 2018 Accepted: 02 October 2018 Published: 19 October 2018

Citation:

Zhang L, Hou X, Sun L, He T, Wei R,

Pang $M$ and Wang $R$ (2018)

Corrigendum: Staphylococcus aureus

Bacteriophage Suppresses

LPS-Induced Inflammation in MAC-T

Bovine Mammary Epithelial Cells.

Front. Microbiol. 9:2511. T4 phage can abolish the ability of the pathogenic virus to induce NF- $\kappa$ B activity (Gorski et al., 2006). In order to prove the relationship between the effects induced by bacteriophages and NF$\kappa \mathrm{B}$, we determined the expression levels and the phosphorylation of the NF- $\kappa \mathrm{B}$ p65 subunit were determined by Western blotting. This part of our work demonstrated that pre-treatment with bacteriophage vB_SauM_JS25 significantly suppressed the phosphorylation levels of NF- $\kappa$ B p65 at $2 \mathrm{~h}$ post-LPS-stimulation ( $p<0.05$, Figure 4 ). However, once the pre-treatment bacteriophage was removed, the LPS-induced production of cytokines was significantly enhanced $(p<0.001$, Figure 3). As reported previously, the lack of dissemination, and the reduced levels of inflammation caused by the production of prophage-created conditions, could promote persistent infection by $P$. aeruginosa (Secor et al., 2017). Moreover, there may be other mechanisms that bacteriophages use to interact directly with eukaryotic systems and thus modulate the immune system. In these scenarios, bacteriophages appear to act an immunomodulator in order to balance inflammation cytokines.

The authors apologize for this error and state that this does not change the scientific conclusions of the article in any way.

The original article has been updated.

\section{REFERENCES}

Gorski, A., Kniotek, M., Perkowska-Ptasinska, A., Mroz, A., Przerwa, A., Gorczyca, W., et al. (2006). Bacteriophages and transplantation tolerance. Transplant. Proc. 38, 331-333. doi: 10.1016/j.transproceed.2005.12.073

Secor, P. R., Michaels, L. A., Smigiel, K. S., Rohani, M. G., Jennings, L. K., Hisert, K. B., et al. (2017). Filamentous bacteriophage produced by Pseudomonas aeruginosa alters the inflammatory response and promotes noninvasive infection in vivo. Infect. Immun. 85:e0648-16. doi: 10.1128/IAI.00648-16

Conflict of Interest Statement: The authors declare that the research was conducted in the absence of any commercial or financial relationships that could be construed as a potential conflict of interest.

Copyright $\odot 2018$ Zhang, Hou, Sun, He, Wei, Pang and Wang. This is an open-access article distributed under the terms of the Creative Commons Attribution License (CC BY). The use, distribution or reproduction in other forums is permitted, provided the original author(s) and the copyright owner(s) are credited and that the original publication in this journal is cited, in accordance with accepted academic practice. No use, distribution or reproduction is permitted which does not comply with these terms. 